\title{
Prevalence and Molecular Characteristics of Drug- Resistant Mycobacterium Tuberculosis in Hainan, China: From 2014 to 2019
}

\section{xiujuan zhao}

Hainan Medical University

Lin Liu

Hainan Medical University

\section{Xingyong Wu}

Hainan Medical University

\section{Sijing Li}

Hainan Medical University, Hainan 571199, China

\section{Biao Liu}

Hainan Medical University

\section{Mamy Jayne Nelly Rajaofera}

Hainan Medical University

\section{Yingfei Zeng}

Hainan Medical University

\section{Sufang Dong}

Hainan Medical University

\section{Zheng Bei}

Hainan Province Geriatric Hospital

\section{Hua Pei}

The Second Affiliated Hospital of Hainan Medical University

Qianfeng Xia ( $\nabla$ xiaqianfeng@hainmu.edu.cn )

Hainan Medical University

\section{Research article}

Keywords: Mycobacterium tuberculosis, CapitalBioTM DNA microarray, Drug sensitivity test, Molecularcharacteristics, Drug-resistant rate

Posted Date: January 25th, 2021

DOl: https://doi.org/10.21203/rs.3.rs-151970/v1 
License: (c) (i) This work is licensed under a Creative Commons Attribution 4.0 International License. Read Full License 


\title{
Prevalence and molecular characteristics of drug-resistant
}

\section{mycobacterium tuberculosis in Hainan, China: From 2014 to} 2019

Lin Liu ${ }^{\mathrm{a}, 1}$, Xiujuan Zhao ${ }^{\mathrm{b}, 1}$, Xingyong $\mathrm{Wu}^{\mathrm{a}}$, Biao Liu ${ }^{\mathrm{a}}$, Mamy Jayne Nelly Rajaofera ${ }^{\mathrm{a}}$, Yingfei Zeng ${ }^{\mathrm{a}}$, Sufang Dong ${ }^{\mathrm{a}}$, Zheng Bei ${ }^{\mathrm{d}}$, Hua Pei ${ }^{\mathrm{c}^{*}}$, Qianfeng Xia ${ }^{\mathrm{a}^{*}}$

${ }^{a}$ Key Laboratory of Tropical Translational Medicine of Ministry of Education and School of Tropical Medicine and Laboratory Medicine, Hainan Medical University, Haikou, Hainan 571199, China.

${ }^{\mathrm{b}}$ Public Health School, Hainan Medical University, Haikou, Hainan 571199, China.

${ }^{\mathrm{c}}$ Department of Clinical Laboratory, The Second Affiliated Hospital, Hainan Medical University, Haikou 570311, China

${ }^{\mathrm{d}}$ Hainan Province cadre sanatorium, Hainan Province Geriatric Hospital, Haikou 571100, China

\section{*Correspondence:}

Corresponding author:

Qianfeng Xia; Mailing address: Hainan Medical University, Haikou, 571199, China. E-mail: xiaqianfeng@hainmc.edu.cn

Hua Pei: Mailing address: Hainan Medical University, Haikou, 571199, China. E-mail: phzmh61@aliyun.com

Number of words: 21875 characters (including spaces)

Number of figures: 2 figures

Number of tables: 4 tables

\begin{abstract}
Background: The emergence of antimicrobial resistance against mycobacterium tuberculosis has become the major concern in global tuberculosis control due to its limited therapy options and high mortality. However, the clinical and molecular
\end{abstract}


characteristics of drug-resistant strains vary in different geographical areas. Hainan Island located in southern China, is a high drug-resistant tuberculosis burden area. This study aimed to determine the dynamic changes of drug-resistance patterns and drug-related gene mutation types of mycobacterium tuberculosis in Hainan from 2014 to 2019.

Results: A total of 1484 culture-confirmed mycobacterium tuberculosis were included in this study. It was found that the proportions of drug resistance to isoniazid and rifampin were $31.3 \%$ and $31.1 \%$ respectively. Overall, the proportion of multidrug resistant mycobacterium tuberculosis was $24.9 \%$. Multivariate logistic regression analysis showed that age and the treatment history were independent influencing factors of drug resistant tuberculosis. The proportions of drug-resistant tuberculosis in retreatment patients were considerably higher than those in new patients. The most common mutation types of isoniazid were Ser315 $\rightarrow$ Thr $(66.3 \%)$, and the most common mutation types of rifampin were Ser531 $\rightarrow$ Leu $(41.5 \%)$.

Conclusions: Our data suggests that the prevalence of drug resistant TB remains high in Hainan, and the risks for developing drug resistance with diversified and complicated mutation types increased significantly in retreatment patients. These results contribute to the knowledge of the prevalence of drug resistance in Hainan Province and also expand the molecular characteristics of drug resistance in China.

Keywords: Mycobacterium tuberculosis; CapitalBio $^{\mathrm{TM}}$ DNA microarray; Drug sensitivity test; Molecular-characteristics; Drug-resistant rate

\section{Introduction}

Mycobacterium tuberculosis (MTB) is a main pathogen of tuberculosis (TB). It can affect almost all human organs, especially the lung [1-3]. The emergence of Drug-resistant mycobacterium tuberculosis (DR-TB), particularly multidrug-resistant mycobacterium tuberculosis (MDR-TB) and extensively drug-resistant mycobacterium tuberculosis (XDR-TB), has been identified as one of the major obstacles to effective TB control in many countries [4, 5]. It was estimated that 10.0 million (range, 9.0-11. 1 million) people fell ill with TB in 2018, according to a newest report from the WHO. And there were approximately half a million (range, 417 000-556000) new cases of rifampin-resistant TB, of which 78\% were MDR-TB.

DR-TB is usually associated with delayed diagnosis, prolonged or ineffective treatment or direct transmission of drug-resistant strains from one individual to another[6, 7].The magnitude and pattern of drug resistance varied greatly with the region because of the huge size of the country, the diverse population density, and the unbalanced economic development in China[8]. Hainan is the southernmost island in China. Separated from the mainland China by the Qiongzhou Strait, the population mobility of Hainan Province is lower than that of other Provinces. MTB of Hainan Province may demonstrate a unique genetic evolution due to the unique geographical location. Unfortunately, thus far, the true magnitude of DR-TB of Hainan Province was not well described to date and should be explored to facilitate control of the TB 
epidemic in this region and throughout China.

To better understand the clinical and molecular characteristics of mycobacterium tuberculosis isolates, we analyzed all strains collected from TB inpatients admitted to the Second Affiliated Hospital of Hainan Medical University from 2014 to 2019. Clinical information, drug-resistant phenotypes and drug-resistance associated mutation types were compared. This study was to evaluate the clinical characteristics and changes in molecular epidemiology of DR-TB.

\section{Results}

\subsection{Demographic and clinical characteristics}

We analyzed the demographic and clinical information of culture-confirmed mycobacterium tuberculosis in Hainan from January 1, 2014 to December 31, 2019. A total of 1484 mycobacterium tuberculosis strains were included, and 923 of which were tested for rifampin and isoniazid drug-resistance gene mutation types by DNA microarray (Figure 1).

\section{Figure 1. Inclusion and Exclusion of the study objects. MTB: mycobacterium tuberculosis; NTB: non-tuberculosis; DST: drug susceptibility test}

Totally $223,171,107,190,331$ and 462 isolates were tested for drug sensitivity from 2014 to 2019, respectively. The mean age of patients was 48 \pm 17.5 (range: 1-95) years old and the gender ratio was 4.6. Gender and contact history showed no statistically significant change using the Chi-square test for trends $(P>0.05)$ while, age and treatment history changed significantly $(P<0.05)$. Compared with results in 2014, the proportion of patients aged between 25 to 64 was significantly higher in 2015 ( $P=$ $0.028)$, the proportion of patients aged over 44 was significantly higher in $2019(P=$ $0.032)$, and the proportion of retreatment cases was significantly higher in $2016(P<$ $0.001)$. What is worth mentioning is that, the proportion of new cases in $2019(61.3 \%)$ was higher than that in $2014(55.6 \%)$ (Table 1$)$.

Table 1 Characteristics of study population from 2014 to 2019

\subsection{Drug susceptibility patterns}

Changes of drug-resistance pattern of MTB from 2014 to 2019 were shown in Table 2. Analysis of the 1484 culture-confirmed TB cases showed that the isoniazid resistant TB rate was $31.3 \%$, the rifampin resistant TB rate was $31.1 \%$, the MDR TB rate was $24.9 \%$, and the XDR-TB rate was $2.2 \%$. In addition, any-drug-resistant TB accounted for $25.8 \%$ of new cases and $67.5 \%$ of retreatment cases. The isoniazid resistant TB accounted for $14.8 \%$ of new cases and $52.0 \%$ of retreatment cases. The rifampin resistant TB accounted for $11.4 \%$ of new cases and $55.7 \%$ of retreatment cases. MDR-TB accounted for $8.6 \%$ of new cases and $45.2 \%$ of retreatment cases. XDR-TB accounted for $0.4 \%$ of new cases and $4.6 \%$ of retreatment cases. For the 
entire study cohort (1484 cases), the longitudinal changes in overall percentage of rifampin (RIF) resistance, kanamycin (KAR) resistance and protionamide (PTO) resistance overtime showed a statistically significant increase using the Chi-square test for trends (Table 2).

To have a better understanding of the epidemic trends in tuberculosis cases with different treatment histories, we explored the changes of drug resistance rate in newly treated patients and retreatment patients respectively. There was no statistical significance in changes of the drug resistance rate in the new TB cases $(P>0.05)$, while in retreatment TB cases, RIF resistance increased at an annual rate of $0.05 \%$ (Chi-square test for trends: $\chi^{2}=14.257, P=0.014$ ), PTO resistance increased at an annual rate of $0.18 \%$ (Chi-square test for trends: $\chi^{2}=35.332, P<0.001$ )(Figure 2).

Table 2 Evaluation and comparison of drug resistance rate of anti-tuberculosis drugs in 2014-2019

Abbreviation: INH, isoniazid; RIF, rifampin; EMB, ethambutol; STR, streptomycin; first-line drug resistance, including isoniazid, rifampin, ethambutol and streptomycin; MDR, multi-drug resistant; CPM, capreomycin; KAR, kanamycin; OFX, ofloxacin; PTO, protionamide; XDR, extensively drug-resistant

Figure 2 Trends of different drug-resistance patterns among 1484 culture-confirmed TB cases in Hainan, 2014 to 2019. In new cases, for INH resistance $\left(\chi^{2}=2.813, P=0.729\right)$; for $R I F$ resistance $\left(\chi^{2}=3.181, P=0.672\right)$; for $\operatorname{MDR}-T B\left(\chi^{2}=4.210, P=0.520\right)$; for XDR-TB $\left(\chi^{2}=4.383, P=0.496\right)$. In retreatment cases, for INH resistance $\left(\chi^{2}=9.512, P=0.090\right)$; for $\mathrm{RIF}$ resistance $\left(\chi^{2}=14.257\right.$, $P=0.014)$; for MDR-TB $\left(\chi^{2}=10.328, P=0.066\right)$; for $X D R-T B\left(\chi^{2}=7.670, P=0.175\right)$. Note: *new cases, **retreatment cases. Abbreviation: INH-R, isoniazid resistance; RIF-R, rifampin resistance; MDR-TB, multidrug resistant mycobacterium tuberculosis; XDR-TB, extensively drug resistant mycobacterium tuberculosis

\subsection{Factors associated with drug-resistance TB}

Both univariate and multivariate analysis showed that age and treatment history were influencing factors for TB patients being resistant to any anti-TB drug, multidrug-resistant or extensive drug-resistant $(P<0.05)$ (Table3). The risk of drug-resistance was associated with lower age. For those aged $>64$ years, the odd ratio to any drug-resistance, MDR and XDR were, respectively, 0.602 (95\%CI: 0.397, 0.913), 0.277 (95\%CI: 0.157, 0.486) and 0.287 (95\%CI: 0.117, 0.702) times of those under 25 years old $(\mathrm{P}=0.017$ for any tested-drug; $\mathrm{P}<0.001$ for $\mathrm{MDR}$; $\mathrm{P}=0.006$ for $\mathrm{XDR})$. Furthermore, the risk of drug-resistant in retreatment cases was significantly higher than that in new cases, and their risk of resistance to any tested-drug, multi-drug-resistant, extensive drug-resistant were respectively, 5.958(95\%CI: 4.738, 7.492), 12.753(95\%CI: 9.349, 17.397) and 16.498(95\%CI: 9.816, 27.728) times 
higher than that in new cases $(P<0.001$ for any tested-drug, $P<0.001$ for multi-drug-resistant, $P<0.001$ for extensive drug-resistant). Compared to people with no exposure history, those who have exposure history may have higher drug resistance rates, and their risk of resistance to any detected drugs were 1.428 (95\% CI: $1.000,2.039)$ times higher than that of the people without contact history $(P=0.050)$.

Table 3 Factors associated with drug-resistance TB

Note: * indicates that the difference is statistically significant compared with 2014. Abbreviation: $95 \%$ CI means $95 \%$ confidence interval

\subsection{Detection of drug resistance-associated mutations by DNA microarray}

The gene mutation profile of tuberculosis resistant strains was further investigated. A total of 923 strains were tested for resistance gene mutations by DNA microarray and the mutation sites were shown in Table 4.

In the isoniazid resistance mutation sites, KatG and promoter inhA were $70.8 \%$ (204/288) and $8.0 \%$ (23/288), and combinatorial mutation of $K a t G+i n h A$ was $1.0 \%$ (3/288), respectively. Kat $G$ was the most common mutation, and its mutation was all higher than $79.0 \%$ from 2017 to 2019. In 2019, the mutation rate of inhA was significantly increased $(15.5 \%, 15 / 97, \mathrm{P}=0.006)$. In addition, the combinatorial mutation of KatG+inhA was only found in 2019.

Among rifampin resistance mutation sites, rpoB531 (43.6\%, 167/383), rpoB526 $(18.3,70 / 383)$ and $r p o B 511(7.0,27 / 383)$ were the most frequent. The mutation rates of rpoB53 isolates from 2017 to 2019 were significantly higher than those from 2014 $(P<0.05)$.

The mutation rates of $r p o B+i n h A$ and $r p o B+r p o B+K a t G$ in MDR-TB strains were $3.3 \%$ (8/242). The $r p o B+K a t G+i n h A$ mutation was only found in three isolates in 2019. While the $r p o B+K a t G$ mutation rate was $71.1 \%$ (172 / 242), rpoB531+ KatG315 mutation in MDR-TB isolates was significantly higher in 2018 (51.2\%, $22 / 43, \mathrm{P}=0.028)$ and $2019(52.7 \%, 39 / 74, \mathrm{P}=0.010)$ than in $2014(7.7 \%, 3 / 39)$.

This study also compared the mutation sites of drug-resistant strains from 2014 to 2019, and some new drug-resistant gene combinations were detected. For isoniazid, combinatorial mutation of Ser315 $\rightarrow T h r+i n h A T \_15$ emerged. For rifampin, combinatorial mutation of Gln513 $\rightarrow$ Pro, Leu511 $\rightarrow$ Pro + Asp516 $\rightarrow$ Val appeared. For MDR-TB strains, Leu511 $\rightarrow$ Pro, Asp516 $\rightarrow$ Val + Ser315 $\rightarrow$ Thr were also found, and the drug-resistant mutation sites were constantly diversified.

Table 4 Evolution of drug resistance mutation sites of mycobacterium tuberculosis to first-line anti tuberculosis drugs isoniazid and rifampin in 2014-2019

Note: * indicates that the difference is statistically significant compared with 2014 
Running Title: Characteristics of drug-resistant Mycobacterium tuberculosis

\section{Discussion}

In 2017, the Southeast Asia and the Western Pacific region saw the largest number of new TB cases, accounting for $62 \%$ of all new cases worldwide. China is one of the three countries with the highest drug-resistant TB in the world. Previous studies have shown that the clinical and molecular characteristics of drug-resistant strains in China vary from region to region[9, 11-18]. Hainan is the only tropical island in China. Its unique tropical climate and relatively low population mobility may affect the infection and drug resistance of tuberculosis. Determining the change in the TB drug-resistance rate over time and its current status in Hainan are essential to adequately administer anti-TB regimens and achieve successful treatment. This study was a large population and long-term-based retrospective study conducted in Hainan Province, China. To our knowledge, this is the first study providing comprehensive assessment of the dynamic changes of drug resistance rate and the mutation sites of isoniazid and rifampin resistance in Hainan Province.

The overall percentage of retreatment cases was $44.4 \%$, while, a review showed that the median percentage of TB patients experiencing an episode of recurrent TB after treatment completion was 3.4\% (interquartile range [IQR] 1.6-6.0, range 0.4-16.7) [19], suggesting that the retreatment cases is still a big challenge in controlling the TB epidemic in Hainan.

The present study show that $44.3 \%$ (658/1484) of patients had drug-resistant disease, meanwhile the proportions of MDR- and XDR-TB among patients were $24.9 \%$ and $2.2 \%$, nearly two times the proportions presented in the data from a China Clinical Tuberculosis Centre in 2017[20]. According to a WHO report, the global MDR/RR-TB (multidrug resistant tuberculosis / rifampin resistant tuberculosis) rate was $3.4 \%$ (95\%CI: $2.5 \%-4.4 \%$ ) for new cases and 18\% (95\%CI: $7.6 \%-31 \%$ ) for retreatment cases in 2018, while in China, the MDR/RR-TB rate was $7.1 \%$ (95\%CI: $5.6 \%-8.7 \%$ ) for new cases and $21 \%$ (95\%CI: $21 \%-21 \%$ ) for retreatment cases in the same year. However, our data showed that, in 2019, the MDR/RR-TB rate was $11.4 \%$ for new cases and $55.7 \%$ for retreatment cases in Hainan, which was significantly higher than the average rate of both the global and China's. It showed a serious epidemic of drug-resistant tuberculosis in Hainan.

The changes of drug resistance rate of new cases were not statistically significant. However, the resistance rates of first-line anti-tuberculosis drugs and second-line anti-tuberculosis drugs increased significantly in retreatment patients with rifampin resistant TB increased from $45.9 \%$ in 2014 to $60.3 \%$ in 2019 and protionamide increased at an annual rate of $0.18 \%$. A higher risk of drug resistance was found among retreatment patients, similar results could be found in other reports[21, 22]. This implies that acquired-drug resistance may play an increasing role in the DR-TB epidemic in Hainan. Hence, some appropriate strategies must be implemented to increase continuity of treatment and reduce the rate of treatment default.

We also found that people older than 64 years of age had a lower risk of any drug-resistant TB, MDR-TB and XDR-TB. This is consistent with the conclusion of a systematic review of European studies which concluded that MDR-TB cases are more 
likely to occur in patients younger than 65 years of age $[23,24]$. The higher risk of getting MDR-TB in people under 65 years may be attributed to the use of RIF for anti-TB treatment from around 1965. TB cases in older patients are usually considered as the infecting strains may be more ancient, and carry a lower risk of becoming resistant to drug, the frequency of DR-TB peaked in young adulthood and the age profile of DR-TB was in agreement with other reports[25].

Several recent studies have examined the contribution of $K a t G$ and inhA promoter mutations in drug-resistant TB isolates, and the results revealed significant geographic diversity across regions[26-28]. This study found that the most common mutation of MDR-TB was $34.7 \%($ Ser531 $\rightarrow$ Leu+ Ser315 $\rightarrow$ Thr), however, a study in Brazil showed that was $41.7 \%$ [29]. In our study, the mutation rate in KatG315 was $71.9 \%$, which was higher than the mutation rates reported in Poland $(66.0 \%)$ and Hebei Province, China $(69.9 \%)[30,31]$. The most common mutation of rifampin was rpoB531 (43.6\%, 167 / 383), which was lower than the results of Isakova Jet $\mathrm{al}(64.8 \%)$ [32]. The regional differences in the frequencies of mutations associated with resistance may reflect the diversity in molecular characteristics of DR-TB isolates circulating in geographically distinct areas, and also provide insights for the development of molecular-based diagnostic tests.

Another interesting finding was that a combined mutation of $K a t G+i n h A$, which was rarely reported before, was identified in the study. Moreover, a simultaneous mutationin $r p o B+K a t G+i n h A$ was also identified, indicating that tuberculosis strains were constantly mutating. These data might be helpful in the design and development of new anti-mycobacterium tuberculosis drugs. There were still some resistant isolates harboring no mutation within the sequenced regions. This implied that these isolates probably harbored mutations outside the sequenced area or that the resistance may be caused by other mechanisms, such as efflux pumps[33].

Due to the limitations of retrospective data collection, the education background, socioeconomic status, and living conditions of the patients involved in this study were not well described and recorded. The interplay of these factors and how could it affect the epidemic of drug-resistant TB are somewhat neglected. Well-designed studies with comprehensive and detailed research data in China should thus be conducted in the future.

\section{Conclusions:}

Despite these limitations, the trends of different drug resistance patterns overtime were examined and a better understanding of the epidemic characteristics of TB cases in Hainan was obtained. First, the drug-resistant TB rate remains high throughout the study. Second, the age and treatment history were independent risk factors of TB drug resistance. Third, different mutation rates and patterns are identified.

\section{Materials and Methods}

\subsection{Study Population and Data Collection}

This study was carried out from January 2014 to December 2019 at the Second Affiliated Hospital of Hainan Medical University, which serves as the sole specialized 
Running Title: Characteristics of drug-resistant Mycobacterium tuberculosis

TB hospital in Hainan. Information for all patients (age, gender, TB contact history, and TB treatment history, etc.) was collected and recorded. Only one isolate per patient was collected and tested.

\subsection{Laboratory pretreatment}

Pulmonary samples were collected by expectoration, gastric aspiration, and sputum induction. Extra pulmonary samples (pleural fluid, spinal fluid, and lymph nodes) were collected by pleural tap, lumbar puncture, lymph node biopsy, fine needle aspiration, and other techniques. The patients' samples were placed in a microcentrifuge tube, and processed for smear and culture. To identify the presence of acid-fast bacilli, we used Ziehl-Neelsen staining (Baso, Zhuhai, China) for smear microscopy. Each sample was inoculated into the acidic modified Lowenstein-Jensen (Cell Biotech Co., Ltd., Hainan, China) culture medium. Strain isolation and identification were performed in a tuberculosis reference laboratory of the Second Affiliated Hospital of Hainan Medical University. All operations strictly comply with standard biosecurity and institutional safety procedures.

\subsection{Drug sensitivity test}

Following cultivation, the MTB was assessed for drug sensitivity using a Lowenstein-Jensen culture medium and the following drug concentrations: isoniazid $(0.2 \mu \mathrm{g} / \mathrm{mL})$, rifampin $(40 \mu \mathrm{g} / \mathrm{mL})$, ethambutol $(2.0 \mu \mathrm{g} / \mathrm{mL})$, streptomycin (4.0 $\mu \mathrm{g} / \mathrm{mL})$, capreomycin $(2 \mu \mathrm{g} / \mathrm{mL})$, kanamycin $(40 \mu \mathrm{g} / \mathrm{mL})$, ofloxacin $(30 \mu \mathrm{g} / \mathrm{mL})$, and protionamide $(40 \mu \mathrm{g} / \mathrm{mL})$. Isolates with growth proportion for $>1 \%$ on medium containing anti-TB drugs compared with the growth on drug free medium were considered to be resistant to those drugs[9].

\subsection{Detection by CapitalBio ${ }^{\mathrm{TM}}$ DNA microarray}

This study was based on MTB drug resistance gene detection kit (CapitalBio $^{\mathrm{TM}}$ DNA microarray method, Beijing CapitalBio Technology, 301035), which can specifically detect the mutations on the promoter of rpoB, KatG and inhA. Laboratory operations were performed according to the manufacturer's instructions [10].

\subsection{Statistical analysis}

The Chi-square test or the Fisher's exact test were chosen to assess the difference between different groups. Univariate and multivariate analysis were used to evaluate the influencing factors related to drug resistance of tuberculosis by SPSS 21.0 software as well. A two-tailed $\mathrm{P}<0.05$ was considered statistically significant.

\section{Abbreviations:}

CPM: capreomycin

DR-TB: Drug-resistant mycobacterium tuberculosis

EMB: ethambutol

INH: isoniazid

KAR: kanamycin

MDR-TB: multidrug-resistant mycobacterium tuberculosis 
Running Title: Characteristics of drug-resistant Mycobacterium tuberculosis

MDR: multi-drug resistant

$$
\text { MTB: mycobacterium tuberculosis }
$$

PTO: protionamide

RIF: rifampin

STR: streptomycin

TB: tuberculosis

XDR-TB: extensively drug-resistant mycobacterium tuberculosis

XDR: extensively drug-resistant

\section{Declarations}

\subsection{Ethical approval and consent to participate}

The study was approved by the Ethic Committee of the Second Affiliated Hospital of Hainan Medical University, Hainan, China. Informed consent was obtained from research subjects, and patient records were anonymized and identified before analysis.

\subsection{Consent for publication}

\section{Not applicable.}

\subsection{Availability of data and materials}

The oligonucleotide probes and primers used in this study available from the corresponding author on reasonable request.

\subsection{Competing interests}

The authors declare that the research was conducted in the absence of any commercial or financial relationships that could be construed as a potential conflict of interest.

\subsection{Funding:}

The work was funded by the National Science and Technology Major Project (2018ZX10101003-001-009), National Natural Science Foundation of China (81960002 and 81860002), School of Tropical Medicine and Laboratory Medicine, Hainan medical University/Research Cultivation fund(1021/XPY180017).

\subsection{Authors' contributions}

All authors contribute equally to this article. All authors read and approved the final manuscript.

\subsection{Acknowledgements}

Not applicable. 


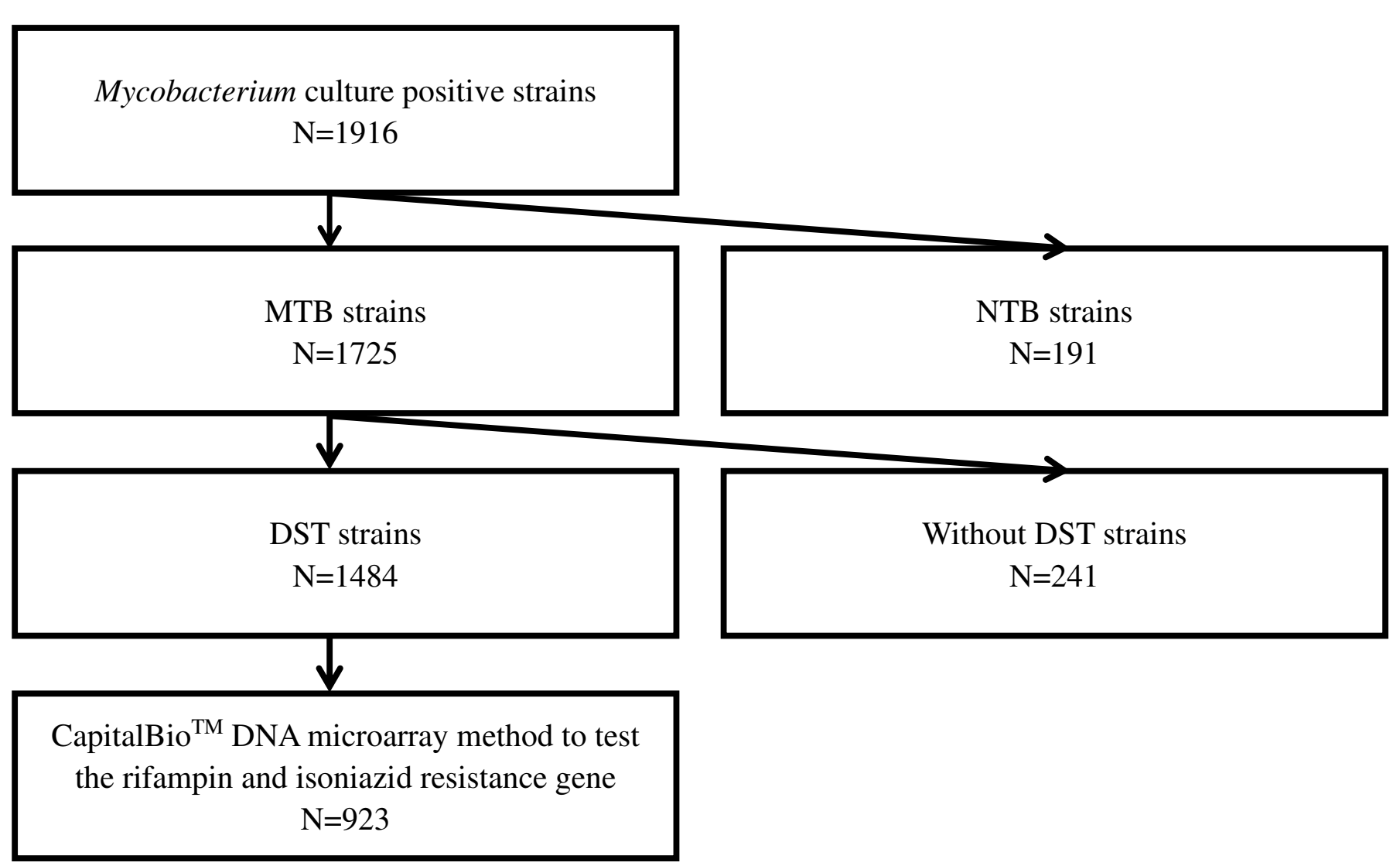

Figure 1. Inclusion and Exclusion of the study objects. MTB: mycobacterium tuberculosis; NTB: non-tuberculosis; DST: drug susceptibility test. 
Running Title: Characteristics of drug-resistant Mycobacterium tuberculosis

\begin{tabular}{|c|c|c|c|c|c|c|c|c|c|}
\hline Characteristics & $\begin{array}{l}\text { Total } \\
\mathrm{n}(\%)\end{array}$ & $\begin{array}{l}2014 \\
\mathrm{n}(\%)\end{array}$ & $\begin{array}{l}2015 \\
\mathrm{n}(\%)\end{array}$ & $\begin{array}{l}2016 \\
\mathrm{n}(\%)\end{array}$ & $\begin{array}{l}2017 \\
\mathrm{n}(\%)\end{array}$ & $\begin{array}{l}2018 \\
\mathrm{n}(\%)\end{array}$ & $\begin{array}{l}2019 \\
\mathrm{n}(\%)\end{array}$ & $\chi^{2}$ & $P$ \\
\hline \multicolumn{10}{|l|}{ Gender } \\
\hline Male & $1217(82.0)$ & $181(81.2)$ & $147(86.0)$ & $84(78.5)$ & $157(82.6)$ & $262(79.2)$ & $386(83.5)$ & 5.433 & 0.365 \\
\hline Female & $267(18.0)$ & $42(18.8)$ & $24(14.0)$ & $23(21.5)$ & $33(17.4)$ & $69(20.8)$ & $76(16.5)$ & & \\
\hline \multicolumn{10}{|l|}{ Age group(years) } \\
\hline$\sim 25$ & 205(13.8) & $42(18.8)$ & $18(10.5)$ & $17(15.9)$ & $34(17.9)$ & $43(13.0)$ & $51(11.0)$ & 25.692 & 0.041 \\
\hline$\sim 44$ & $375(25.3)$ & $55(24.7)$ & $55(32.2)$ & $26(24.3)$ & $43(22.6)$ & $88(26.6)$ & $108(23.4)$ & & \\
\hline$\sim 64$ & $635(42.8)$ & $88(39.5)$ & $78(45.6)$ & $48(44.9)$ & $81(42.6)$ & $130(39.3)$ & $210(45.5)$ & & \\
\hline$>64$ & $269(18.1)$ & $38(17.0)$ & $20(11.7)$ & $16(15.0)$ & $32(16.8)$ & $70(21.1)$ & $93(20.1)$ & & \\
\hline \multicolumn{10}{|l|}{ Treatment history } \\
\hline New cases & $825(55.6)$ & $125(56.1)$ & $88(51.5)$ & $39(36.4)$ & $94(49.5)$ & $196(59.2)$ & $283(61.3)$ & 27.727 & $<0.001$ \\
\hline Retreatment cases & $659(44.4)$ & 98(43.9) & $83(48.5)$ & $68(63.6)$ & $96(50.5)$ & $135(40.8)$ & $179(38.7)$ & & \\
\hline \multicolumn{10}{|l|}{ Contact history } \\
\hline No & 1313(88.5) & $206(92.4)$ & 154(90.1) & $90(84.1)$ & 167(87.9) & $285(86.1)$ & $411(89.0)$ & 7.745 & 0.171 \\
\hline Yes & 171(11.5) & $17(7.6)$ & $117(9.9)$ & $17(15.9)$ & $23(12.1)$ & $46(13.9)$ & $51(11.0)$ & & \\
\hline \multirow{2}{*}{ Total } & 1484 & 223 & 171 & 107 & 190 & 331 & 462 & & \\
\hline & $(100.0)$ & $(100.0)$ & $(100.0)$ & $(100.0)$ & $(100.0)$ & $(100.0)$ & $(100.0)$ & & \\
\hline
\end{tabular}

396 
Running Title: Characteristics of drug-resistant Mycobacterium tuberculosis

Table 2 Evaluation and comparison of drug resistance rate of anti-tuberculosis drugs in 2014-2019

\begin{tabular}{|c|c|c|c|c|c|c|c|c|c|}
\hline Category & $\begin{array}{l}2014 \\
\mathrm{n}(\%)\end{array}$ & $\begin{array}{l}2015 \\
\mathrm{n}(\%)\end{array}$ & $\begin{array}{l}2016 \\
\mathrm{n}(\%)\end{array}$ & $\begin{array}{l}2017 \\
\mathrm{n}(\%)\end{array}$ & $\begin{array}{l}2018 \\
\mathrm{n}(\%)\end{array}$ & $\begin{array}{l}2019 \\
\mathrm{n}(\%)\end{array}$ & $\begin{array}{l}\text { Total } \\
\text { n (\%) }\end{array}$ & $\chi^{2}$ & $P$ \\
\hline \multicolumn{10}{|l|}{ All TB cases } \\
\hline Any drug-resistance & $95(42.6)$ & $85(49.7)$ & $60(56.1)$ & $96(50.5)$ & 127(38.4) & $195(42.2)$ & $658(44.3)$ & 16.820 & 0.005 \\
\hline INH & 71(31.8) & $67(39.2)$ & $42(39.3)$ & $68(35.8)$ & $85(25.7)$ & $132(28.6)$ & $465(31.3)$ & 16.349 & 0.006 \\
\hline RIF & $60(26.9)$ & $63(36.8)$ & $48(44.9)$ & $68(35.8)$ & $86(26.0)$ & $136(29.4)$ & $461(31.1)$ & 20.521 & 0.001 \\
\hline EMB & $23(10.3)$ & $12(7.0)$ & $20(18.7)$ & $26(13.7)$ & $26(7.9)$ & $41(8.9)$ & $148(10.0)$ & 15.941 & 0.007 \\
\hline STR & $48(21.5)$ & $39(22.8)$ & $24(22.4)$ & $50(26.3)$ & $56(16.9)$ & $98(21.2)$ & $315(21.2)$ & 6.977 & 0.222 \\
\hline MDR & $54(24.2)$ & $50(29.2)$ & $38(35.5)$ & $53(27.9)$ & $63(19.0)$ & $111(24.0)$ & $369(24.9)$ & 15.430 & 0.009 \\
\hline Any second-line drug resistance & $42(18.8)$ & $43(25.1)$ & $34(31.8)$ & $46(24.2)$ & $47(14.2)$ & $96(20.8)$ & $308(20.8)$ & 20.435 & 0.001 \\
\hline CPM & $2(0.9)$ & $3(1.8)$ & $3(2.8)$ & $7(3.7)$ & $6(1.8)$ & $21(4.5)$ & $42(2.8)$ & 10.443 & 0.064 \\
\hline KAR & $6(2.7)$ & $5(2.9)$ & $7(6.5)$ & $13(6.8)$ & $6(1.8)$ & $14(3.0)$ & $51(3.4)$ & 13.119 & 0.022 \\
\hline OFX & $38(17.0)$ & $41(24.0)$ & $33(30.8)$ & $42(22.1)$ & $43(13.0)$ & $76(16.5)$ & $273(18.4)$ & 24.208 & $<0.001$ \\
\hline PTO & $1(0.4)$ & $1(0.6)$ & $0(0.0)$ & $0(0.0)$ & $0(0.0)$ & $18(3.9)$ & $20(1.3)$ & 34.796 & $<0.001$ \\
\hline XDR & $4(1.8)$ & $3(1.8)$ & $5(4.7)$ & $10(5.3)$ & $4(1.2)$ & $7(1.5)$ & $33(2.2)$ & 11.580 & 0.041 \\
\hline \multicolumn{10}{|l|}{ New cases } \\
\hline Any drug-resistance & $35(28.0)$ & $22(25.0)$ & $13(33.3)$ & $29(30.9)$ & $47(24.0)$ & $67(23.7)$ & $213(25.8)$ & 3.759 & 0.585 \\
\hline INH & $22(17.6)$ & $14(15.9)$ & $6(15.4)$ & $17(18.1)$ & $27(13.8)$ & $36(12.7)$ & $122(14.8)$ & 2.813 & 0.729 \\
\hline RIF & $15(12.0)$ & $8(9.1)$ & $7(17.9)$ & $13(13.8)$ & $23(11.7)$ & $28(9.9)$ & $94(11.4)$ & 3.181 & 0.672 \\
\hline EMB & $6(4.8)$ & $2(2.3)$ & $1(2.6)$ & $4(4.3)$ & $6(3.1)$ & $11(3.9)$ & $30(3.6)$ & 1.462 & 0.917 \\
\hline STR & $17(13.6)$ & $9(10.2)$ & $6(15.4)$ & $13(13.8)$ & $25(12.8)$ & $31(11.0)$ & $101(12.2)$ & 1.604 & 0.901 \\
\hline MDR & $14(11.2)$ & $4(4.5)$ & $5(12.8)$ & $8(8.5)$ & $15(7.7)$ & $25(8.8)$ & $71(8.6)$ & 4.210 & 0.520 \\
\hline Any second-line drug resistance & $13(10.4)$ & $7(8.0)$ & $7(17.9)$ & $11(11.7)$ & $12(6.1)$ & $26(9.2)$ & $76(9.2)$ & 6.397 & 0.270 \\
\hline CPM & $1(0.8)$ & $1(1.1)$ & $0(0.0)$ & $3(3.2)$ & $3(1.5)$ & $7(2.5)$ & $15(1.8)$ & 4.133 & 0.530 \\
\hline KAR & $2(1.6)$ & $1(1.1)$ & $0(0.0)$ & $4(4.3)$ & $1(0.5)$ & $6(2.1)$ & $14(1.7)$ & 6.696 & 0.244 \\
\hline OFX & $10(8.0)$ & $7(8.0)$ & $7(17.9)$ & $8(8.5)$ & $10(5.1)$ & $17(6.0)$ & $59(7.2)$ & 7.388 & 0.193 \\
\hline РTO & $0(0.0)$ & $0(0.0)$ & $0(0.0)$ & $0(0.0)$ & $0(0.0)$ & $2(0.7)$ & $2(0.2)$ & 4.289 & 0.509 \\
\hline XDR & $0(0.0)$ & $1(1.1)$ & $0(0.0)$ & $1(1.1)$ & $0(0.0)$ & $1(0.4)$ & $3(0.4)$ & 4.383 & 0.496 \\
\hline
\end{tabular}


Running Title: Characteristics of drug-resistant Mycobacterium tuberculosis

\begin{tabular}{|c|c|c|c|c|c|c|c|c|c|}
\hline Any drug-resistance & $60(61.2)$ & 63(75.9) & $47(69.1)$ & $67(69.8)$ & $80(59.3)$ & $128(71.5)$ & $445(67.5)$ & 10.236 & 0.069 \\
\hline INH & $49(50.0)$ & $53(63.9)$ & $36(52.9)$ & $51(53.1)$ & $58(43.0)$ & $96(53.6)$ & $343(52.0)$ & 9.512 & 0.090 \\
\hline RIF & $45(45.9)$ & $55(66.3)$ & $41(60.3)$ & $55(57.3)$ & $63(46.7)$ & $108(60.3)$ & $367(55.7)$ & 14.257 & 0.014 \\
\hline EMB & $17(17.3)$ & $10(12.0)$ & 19(27.9) & $22(22.9)$ & $20(14.8)$ & $30(16.8)$ & $118(17.9)$ & 9.294 & 0.098 \\
\hline STR & $31(31.6)$ & $30(36.1)$ & $18(26.5)$ & $37(38.5)$ & $31(23.0)$ & 67(37.4) & $214(32.5)$ & 10.845 & 0.055 \\
\hline MDR & $40(40.8)$ & $46(55.4)$ & $33(48.5)$ & $45(46.9)$ & $48(35.6)$ & $86(48.0)$ & $298(45.2)$ & 10.328 & 0.066 \\
\hline Any second-line drug resistance & 29(29.6) & $36(43.4)$ & 27(39.7) & $35(36.5)$ & $35(25.9)$ & 70(39.1) & $232(35.2)$ & 10.741 & 0.057 \\
\hline CPM & $1(1.0)$ & $2(2.4)$ & $3(4.4)$ & $4(4.2)$ & $3(2.2)$ & $14(7.8)$ & $27(4.1)$ & 10.541 & 0.061 \\
\hline KAR & $4(4.1)$ & $4(4.8)$ & $7(10.3)$ & $9(9.4)$ & $5(3.7)$ & $8(4.5)$ & $37(5.6)$ & 6.544 & 0.257 \\
\hline OFX & 28(28.6) & $34(41.0)$ & $26(38.2)$ & $34(35.4)$ & $33(24.4)$ & 59(33.0) & $214(32.5)$ & 8.806 & 0.117 \\
\hline PTO & $1(1.0)$ & $1(1.2)$ & $0(0.0)$ & $0(0.0)$ & $0(0.0)$ & $16(8.9)$ & $18(2.7)$ & 35.332 & $<0.001$ \\
\hline XDR & $4(4.1)$ & $2(2.4)$ & $5(7.4)$ & $9(9.4)$ & $4(3.0)$ & $6(3.4)$ & $30(4.6)$ & 7.670 & 0.175 \\
\hline
\end{tabular}

Abbreviation: INH, isoniazid; RIF, rifampin; EMB, ethambutol; STR, streptomycin; first-line drug resistance, including isoniazid, rifampin, ethambutol and streptomycin; MDR, multi-drug resistant; CPM, capreomycin; KAR, kanamycin; OFX, ofloxacin; PTO, protionamide; XDR, extensively drug-resistant 


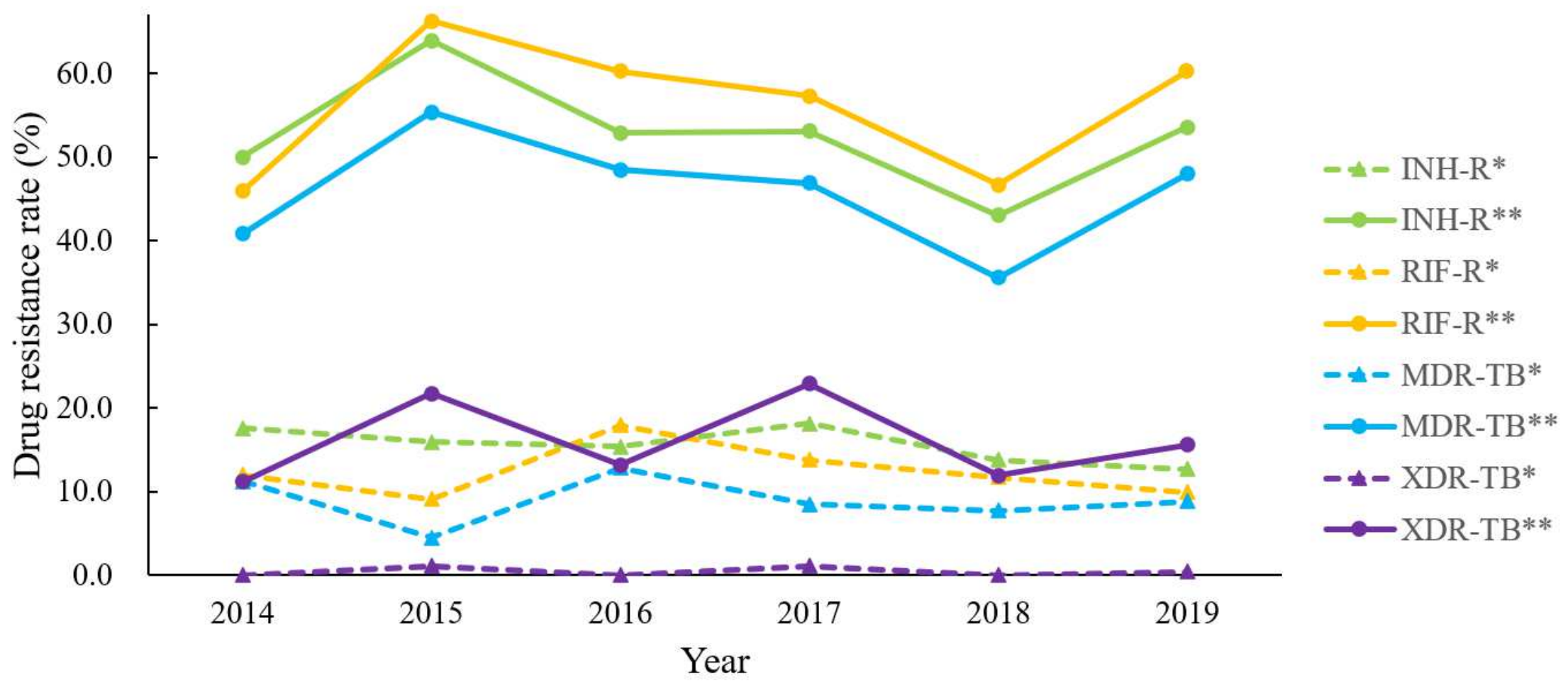


Running Title: Characteristics of drug-resistant Mycobacterium tuberculosis

Table 3Factors associated with drug-resistance TB

\begin{tabular}{|c|c|c|c|c|c|c|c|c|c|c|c|c|c|c|c|c|}
\hline \multirow[b]{2}{*}{ Factors } & \multirow{2}{*}{$\begin{array}{l}\text { Any } \\
\text { drug } \\
\text { resistant } \\
\mathrm{TB} \\
(\mathrm{n}=658)\end{array}$} & \multirow[b]{2}{*}{$\begin{array}{l}\text { MDR-TB } \\
(n=369)\end{array}$} & \multirow[b]{2}{*}{$\begin{array}{l}\text { XDR-TB } \\
(\mathrm{n}=123)\end{array}$} & \multirow[b]{2}{*}{$\begin{array}{l}\text { Pan-susceptibl } \\
\text { e TB } \\
(\mathrm{n}=826)\end{array}$} & \multicolumn{4}{|c|}{ Any drug resistant TB VS Pan-susceptible TB } & \multicolumn{4}{|c|}{ MDR-TB VS Pan-susceptible TB } & \multicolumn{4}{|c|}{ XDR-TB VS Pan-susceptible TB } \\
\hline & & & & & $\begin{array}{l}\text { OR } \\
(95 \% \mathrm{CI})\end{array}$ & $P$ & $\begin{array}{l}\text { Adjusted } \\
\text { OR } \\
(95 \% \mathrm{CI})\end{array}$ & $P$ & $\begin{array}{l}\text { OR } \\
(95 \% \mathrm{CI})\end{array}$ & $P$ & $\begin{array}{l}\text { Adjusted OR } \\
(95 \% \mathrm{CI})\end{array}$ & $P$ & $\begin{array}{l}\text { OR } \\
(95 \% \mathrm{CI})\end{array}$ & $P$ & $\begin{array}{l}\text { Adjusted OR } \\
(95 \% \mathrm{CI})\end{array}$ & $P$ \\
\hline \multicolumn{17}{|l|}{ Gender } \\
\hline Male & $\begin{array}{l}534(81.2 \\
)\end{array}$ & $299(81.0)$ & $97(78.9)$ & $683(82.7)$ & Reference & & & & Reference & & & & Reference & & & \\
\hline Female & $\begin{array}{l}124(18.8 \\
)\end{array}$ & $70(19.0)$ & $26(21.1)$ & $143(17.3)$ & $\begin{array}{l}0.830 \\
(0.614,1.121 \\
)\end{array}$ & 0.225 & & & $\begin{array}{l}0.820 \\
(0.555,1.209)\end{array}$ & 0.316 & & & $\begin{array}{l}0.673 \\
(0.387,1.172)\end{array}$ & 0.162 & & \\
\hline \multicolumn{17}{|l|}{ Age (years) } \\
\hline$\sim 25$ & $84(12.8)$ & $52(14.1)$ & $15(12.2)$ & 121(14.6) & Reference & & Reference & & Reference & & Reference & & Reference & & Reference & \\
\hline$\sim 44$ & $\begin{array}{l}173(26.3 \\
)\end{array}$ & $100(27.1)$ & $31(25.2)$ & $202(24.5)$ & $\begin{array}{l}1.080 \\
(0.737,1.582 \\
)\end{array}$ & 0.694 & $\begin{array}{l}1.052 \\
(0.720,1.536 \\
)\end{array}$ & 0.795 & $\begin{array}{l}0.955 \\
(0.588,1.550)\end{array}$ & 0.852 & $\begin{array}{l}0.917 \\
(0.568,1.482)\end{array}$ & 0.725 & $\begin{array}{l}1.129 \\
(0.540,2.363)\end{array}$ & 0.747 & $\begin{array}{l}1.062 \\
(0.511,2.205)\end{array}$ & 0.873 \\
\hline$\sim 64$ & $\begin{array}{l}311(47.3 \\
)\end{array}$ & $183(49.6)$ & $67(54.5)$ & $324(39.2)$ & $\begin{array}{l}1.079 \\
(0.753,1.544 \\
)\end{array}$ & 0.679 & $\begin{array}{l}1.039 \\
(0.730,1.479 \\
)\end{array}$ & 0.833 & $\begin{array}{l}0.941 \\
(0.598,1.480)\end{array}$ & 0.791 & $\begin{array}{l}0.886 \\
(0.568,1.328)\end{array}$ & 0.593 & $\begin{array}{l}1.329 \\
(0.674,2.622)\end{array}$ & 0.412 & $\begin{array}{l}1.227 \\
(0.629,2.390)\end{array}$ & 0.549 \\
\hline$>64$ & $90(13.7)$ & $34(9.2)$ & $10(8.1)$ & 179(21.7) & $\begin{array}{l}0.626 \\
(0.410,0.954 \\
)\end{array}$ & 0.030 & $\begin{array}{l}0.602 \\
(0.397,0.913 \\
)\end{array}$ & 0.017 & $\begin{array}{l}0.300 \\
(0.169,0.533)\end{array}$ & $<0.001$ & $\begin{array}{l}0.277 \\
(0.157,0.486)\end{array}$ & $<0.001$ & $\begin{array}{l}0.317 \\
(0.128,0.786)\end{array}$ & 0.013 & $\begin{array}{l}0.287 \\
(0.117,0.702)\end{array}$ & 0.006 \\
\hline \multicolumn{17}{|l|}{ Treatment } \\
\hline history & & & & & & & & & & & & & & & & \\
\hline New cases & $\begin{array}{l}213(32.4 \\
)\end{array}$ & $71(19.2)$ & 19(15.4) & $612(74.1)$ & Reference & & Reference & & Reference & & Reference & & Reference & & Reference & \\
\hline $\begin{array}{l}\text { Retreatment } \\
\text { cases }\end{array}$ & $\begin{array}{l}445(67.6 \\
)\end{array}$ & $298(80.8)$ & 104(84.6) & 214(25.9) & $\begin{array}{l}5.992 \\
(4.763,7.538 \\
)\end{array}$ & $\begin{array}{l}<0.00 \\
1\end{array}$ & $\begin{array}{l}5.958 \\
(4.738,7.492 \\
)\end{array}$ & $<0.001$ & $\begin{array}{l}12.777 \\
(9.356,17.448 \\
)\end{array}$ & $<0.001$ & $\begin{array}{l}12.753 \\
(9.349,17.397 \\
)\end{array}$ & $<0.001$ & $\begin{array}{l}16.778 \\
(9.959,28.268 \\
)\end{array}$ & $\begin{array}{l}<0.00 \\
1\end{array}$ & $\begin{array}{l}16.498 \\
(9.816,27.728 \\
)\end{array}$ & $\begin{array}{l}<0.00 \\
1\end{array}$ \\
\hline
\end{tabular}


Running Title: Characteristics of drug-resistant Mycobacterium tuberculosis

Contact history

\begin{tabular}{|c|c|c|c|c|c|c|c|c|c|c|}
\hline $\begin{array}{l}565(85.9 \\
\quad)\end{array}$ & $317(85.9)$ & $108(87.8)$ & $748(90.6)$ & Reference & & Reference & & Reference & Reference & Reference \\
\hline $93(14.1)$ & $52(14.1)$ & $15(12.2)$ & 78(9.4) & $\begin{array}{l}1.408 \\
(0.985,2.014\end{array}$ & 0.060 & $\begin{array}{l}1.428 \\
(1.000,2.039\end{array}$ & 0.050 & $\begin{array}{l}1.247 \\
(0.794,1.960)\end{array}$ & 0.338 & $\begin{array}{l}1.049 \\
(0.532,2.069)\end{array}$ \\
\hline
\end{tabular}

Note: * indicates that the difference is statistically significant compared with 2014

431

Table 4 Evolution of drug resistance mutation sites of mycobacterium tuberculosis to first-line anti tuberculosis drugs isoniazid and rifampin in $2014-2019$

\begin{tabular}{|c|c|c|c|c|c|c|c|c|c|c|}
\hline \multirow{2}{*}{ Drug } & \multirow{2}{*}{ Locus } & \multirow{2}{*}{ Nucleic acid change } & \multirow{2}{*}{ Codon mutation } & \multirow{2}{*}{$\begin{array}{l}2014 \\
\mathrm{n}(\%)\end{array}$} & \multirow{2}{*}{$\begin{array}{l}2015 \\
\mathrm{n}(\%)\end{array}$} & \multirow{2}{*}{$\begin{array}{l}2016 \\
\mathrm{n}(\%)\end{array}$} & \multirow{2}{*}{$\begin{array}{l}2017 \\
\mathrm{n}(\%)\end{array}$} & \multirow{2}{*}{$\begin{array}{l}2018 \\
\mathrm{n}(\%)\end{array}$} & \multirow{2}{*}{$\begin{array}{l}2019 \\
\mathrm{n}(\%)\end{array}$} & \multirow{2}{*}{ Total } \\
\hline & & & & & & & & & & \\
\hline \multirow[t]{5}{*}{ INH } & $K a t G$ & $\mathrm{AGC} \rightarrow \mathrm{AAC}$ & Ser315Asn & $4(10.0)$ & $0(0.0)^{*}$ & $0(0.0)^{*}$ & $1(2.7)$ & $3(6.3)$ & $5(5.2)$ & $13(4.5)$ \\
\hline & & $\mathrm{AGC} \rightarrow \mathrm{ACC}$ & Ser315Thr & $30(75.0)$ & $5(11.1)$ & $10(47.6)$ & $34(91.9)$ & $40(83.3)$ & $72(74.2)$ & $191(66.3)$ \\
\hline & $\operatorname{inh} A$ & $\mathrm{C} \rightarrow \mathrm{T}$ & $C(-15) \rightarrow T$ & $0(0.0)$ & $0(0.0)$ & $1(4.8)$ & $2(5.4)$ & $5(10.4)$ & $15(15.5)^{*}$ & $23(8.0)$ \\
\hline & $\begin{array}{l}\text { KatG+ } \\
\text { inhA }\end{array}$ & $\begin{array}{l}\mathrm{AGC} \rightarrow \mathrm{ACC} \\
\mathrm{C} \rightarrow \mathrm{T}\end{array}$ & $\begin{array}{l}\text { Ser315Thr+ } \\
C(-15) \rightarrow T\end{array}$ & $0(0.0)$ & $0(0.0)$ & $0(0.0)$ & $0(0.0)$ & $0(0.0)$ & $3(3.1)$ & $3(1.0)$ \\
\hline & Other locus & Other mutations & $\begin{array}{l}\text { Other } \\
\text { substitutions }\end{array}$ & $6(15.0)$ & $40(88.9)^{*}$ & $10(47.6)^{*}$ & $0(0.0)^{*}$ & $0(0.0)^{*}$ & $2(2.1)^{*}$ & $58(20.1)$ \\
\hline Total & & & & $40(100.0)$ & $45(100.0)$ & $21(100.0)$ & $37(100.0)$ & $48(100.0)$ & $97(100.0)$ & $288(100$. \\
\hline \multicolumn{11}{|l|}{ RIF } \\
\hline & rров & $\mathrm{CTG} \rightarrow \mathrm{CCG}$ & Leu511Pro & $8(17.0)$ & $1(1.8)^{*}$ & $1(2.6)^{*}$ & $3(6.4)$ & $4(5.8)$ & $10(8.1)$ & $27(7.1)$ \\
\hline & & $\mathrm{CAA} \rightarrow \mathrm{CCA}$ & Gln513Pro & $0(0.0)$ & $0(0.0)$ & $0(0.0)$ & $0(0.0)$ & $0(0.0)$ & $1(0.8)$ & $1(0.3)$ \\
\hline & & $\mathrm{CAA} \rightarrow \mathrm{AAA}$ & Gln513Lys & $2(4.3)$ & $0(0.0)$ & 1(2.6) & $1(2.1)$ & $1(1.5)$ & $0(0.0)$ & $5(1.3)$ \\
\hline & & $\mathrm{GAC} \rightarrow \mathrm{GGC}$ & Asp516Gly & $0(0.0)$ & $1(1.8)$ & $0(0.0)$ & $0(0.0)$ & $1(1.5)$ & $2(1.6)$ & $4(1.0)$ \\
\hline & & $\mathrm{GAC} \rightarrow \mathrm{GTC}$ & Asp516Val & $4(8.5)$ & $1(1.8)$ & $0(0.0)$ & $2(4.3)$ & $2(2.9)$ & $3(2.4)$ & $12(3.1)$ \\
\hline & & $\mathrm{GAC} \rightarrow \mathrm{TAC}$ & Asp516Tyr & $0(0.0)$ & $0(0.0)$ & $0(0.0)$ & $2(4.3)$ & $1(1.5)$ & $2(1.6)$ & $5(1.3)$ \\
\hline & & $\mathrm{CAC} \rightarrow \mathrm{CGC}$ & His526Arg & $1(2.1)$ & $0(0.0)^{*}$ & 1(2.6) & $1(2.1)$ & $4(5.8)$ & $1(0.8)$ & $8(2.1)$ \\
\hline & & $\mathrm{CAC} \rightarrow \mathrm{CTC}$ & His526Leu & $1(2.1)$ & $0(0.0)$ & $1(2.6)$ & $1(2.1)$ & $3(4.4)$ & $1(0.8)$ & $7(1.8)$ \\
\hline
\end{tabular}


Running Title: Characteristics of drug-resistant Mycobacterium tuberculosis

\begin{tabular}{|c|c|c|c|c|c|c|c|c|c|}
\hline & $\mathrm{CAC} \rightarrow \mathrm{GAC}$ & His526Asp & $4(8.5)$ & $1(1.8)$ & $0(0.0)$ & $4(8.5)$ & $4(5.8)$ & $10(8.1)$ & $23(6.0)$ \\
\hline & $\mathrm{CAC} \rightarrow \mathrm{TAC}$ & His526Tyr & $3(6.4)$ & $1(1.8)$ & $1(2.6)$ & $5(10.6)$ & $9(13.0)$ & $13(10.5)$ & $32(8.4)$ \\
\hline & $\mathrm{TCG} \rightarrow \mathrm{TGG}$ & Ser531Trp & $2(4.3)$ & $1(1.8)^{*}$ & $0(0.0)$ & $1(2.1)^{*}$ & $3(4.4)^{*}$ & $1(0.8)^{*}$ & $8(2.1)$ \\
\hline & $\mathrm{TCG} \rightarrow \mathrm{TTG}$ & Ser531Leu & $12(25.5)$ & $5(8.8)$ & $14(35.9)$ & $25(53.2)$ & $34(49.3)$ & $69(55.6)$ & $159(41.5)$ \\
\hline & $\mathrm{CTG} \rightarrow \mathrm{CCG}$ & Leu533Pro & $0(0.0)$ & $1(1.8)$ & $0(0.0)$ & $0(0.0)$ & $2(2.9)$ & $5(4.0)$ & $8(2.1)$ \\
\hline & $\begin{array}{l}\mathrm{CTG} \rightarrow \mathrm{CCG}^{+} \\
\mathrm{GAC} \rightarrow \mathrm{GGC}\end{array}$ & $\begin{array}{l}\text { Leu511Pro+ } \\
\text { Asp516Gly }\end{array}$ & $1(2.1)$ & $0(0.0)$ & $0(0.0)$ & $1(2.1)$ & $0(0.0)$ & $0(0.0)$ & $2(0.5)$ \\
\hline & $\begin{array}{l}\mathrm{CTG} \rightarrow \mathrm{CCG}^{+} \\
\mathrm{GAC} \rightarrow \mathrm{TAC}\end{array}$ & $\begin{array}{l}\text { Leu511Pro+ } \\
\text { Asp516Tyr }\end{array}$ & $1(2.1)$ & $0(0.0)$ & $0(0.0)$ & $0(0.0)$ & $0(0.0)$ & $0(0.0)$ & $1(0.3)$ \\
\hline & $\begin{array}{l}\mathrm{CTG} \rightarrow \mathrm{CCG}^{+} \\
\mathrm{GAC} \rightarrow \mathrm{GTC}^{-}\end{array}$ & $\begin{array}{l}\text { Leu511Pro+ } \\
\text { Asp516Val }\end{array}$ & $0(0.0)$ & $0(0.0)$ & $0(0.0)$ & $0(0.0)$ & $0(0.0)$ & $1(0.8)$ & $1(0.3)$ \\
\hline & $\begin{array}{l}\mathrm{CTG} \rightarrow \mathrm{CCG}^{+} \\
\mathrm{CAC} \rightarrow \mathrm{TAC}\end{array}$ & $\begin{array}{l}\text { Leu511Pro+ } \\
\text { His526Tyr }\end{array}$ & $0(0.0)$ & $0(0.0)$ & $0(0.0)$ & $0(0.0)$ & $0(0.0)$ & $2(1.6)$ & $2(0.5)$ \\
\hline & $\begin{array}{l}\mathrm{CAA} \rightarrow \mathrm{CCA}^{+} \\
\mathrm{GAC} \rightarrow \mathrm{GTC}\end{array}$ & $\begin{array}{l}\text { Gln513Pro+ } \\
\text { Asp516Val }\end{array}$ & $0(0.0)$ & $0(0.0)$ & $0(0.0)$ & $0(0.0)$ & $0(0.0)$ & $1(0.8)$ & $1(0.3)$ \\
\hline & $\begin{array}{l}\mathrm{GAC} \rightarrow \mathrm{GGC}+ \\
\mathrm{CTG} \rightarrow \mathrm{CCG}\end{array}$ & $\begin{array}{l}\text { Asp516Gly+ } \\
\text { Leu533Pro }\end{array}$ & $2(4.3)$ & $0(0.0)$ & $0(0.0)$ & $0(0.0)$ & $0(0.0)$ & $1(0.8)$ & $3(0.8)$ \\
\hline Other locus & Other mutations & $\begin{array}{l}\text { Other } \\
\text { substitutions }\end{array}$ & $6(12.8)$ & $45(79.0)^{*}$ & $20(51.3)^{*}$ & $1(2.1)$ & $1(1.5)^{*}$ & $1(0.8)^{*}$ & $74(19.3)$ \\
\hline & & & $47(100.0)$ & $57(100.0)$ & $39(100.0)$ & $47(100.0)$ & $69(100.0)$ & $124(100.0)$ & $383(100.0)$ \\
\hline $\begin{array}{l}\text { rpoB+ } \\
\text { KatG }\end{array}$ & $\begin{array}{l}\mathrm{CTG} \rightarrow \mathrm{CCG} \\
\mathrm{AGC} \rightarrow \mathrm{ACC}\end{array}$ & $\begin{array}{l}\text { Leu } 511 \text { Pro+ } \\
\text { Ser315Thr }\end{array}$ & $8(21.6)$ & $0(0.0)^{*}$ & $0(0.0)^{*}$ & $0(0.0)^{*}$ & $3(7.0)$ & $6(8.1)$ & $17(7.0)$ \\
\hline & $\begin{array}{l}\mathrm{GAC} \rightarrow \mathrm{GGC} \\
\mathrm{AGC} \rightarrow \mathrm{AAC}\end{array}$ & $\begin{array}{l}\text { Asp516Gly+ } \\
\text { Ser315Asn }\end{array}$ & $0(0.0)$ & $0(0.0)$ & $0(0.0)$ & $0(0.0)$ & $0(0.0)$ & $1(1.4)$ & $1(0.4)$ \\
\hline & $\begin{array}{l}\mathrm{GAC} \rightarrow \mathrm{GGC} \\
\mathrm{AGC} \rightarrow \mathrm{ACC}\end{array}$ & $\begin{array}{l}\text { Asp } 516 G l y+ \\
\text { Ser } 315 T h r\end{array}$ & $0(0.0)$ & $0(0.0)$ & $0(0.0)$ & $0(0.0)$ & $0(0.0)$ & $1(1.4)$ & $1(0.4)$ \\
\hline & $\begin{array}{l}\mathrm{GAC} \rightarrow \mathrm{GTC} \\
\mathrm{AGC} \rightarrow \mathrm{ACC}\end{array}$ & $\begin{array}{l}\text { Asp516Val+ } \\
\text { Ser315Thr }\end{array}$ & $3(8.1)$ & $0(0.0)$ & $0(0.0)$ & $1(3.5)$ & $2(4.7)$ & $1(1.4)$ & $7(2.9)$ \\
\hline
\end{tabular}


Running Title: Characteristics of drug-resistant Mycobacterium tuberculosis

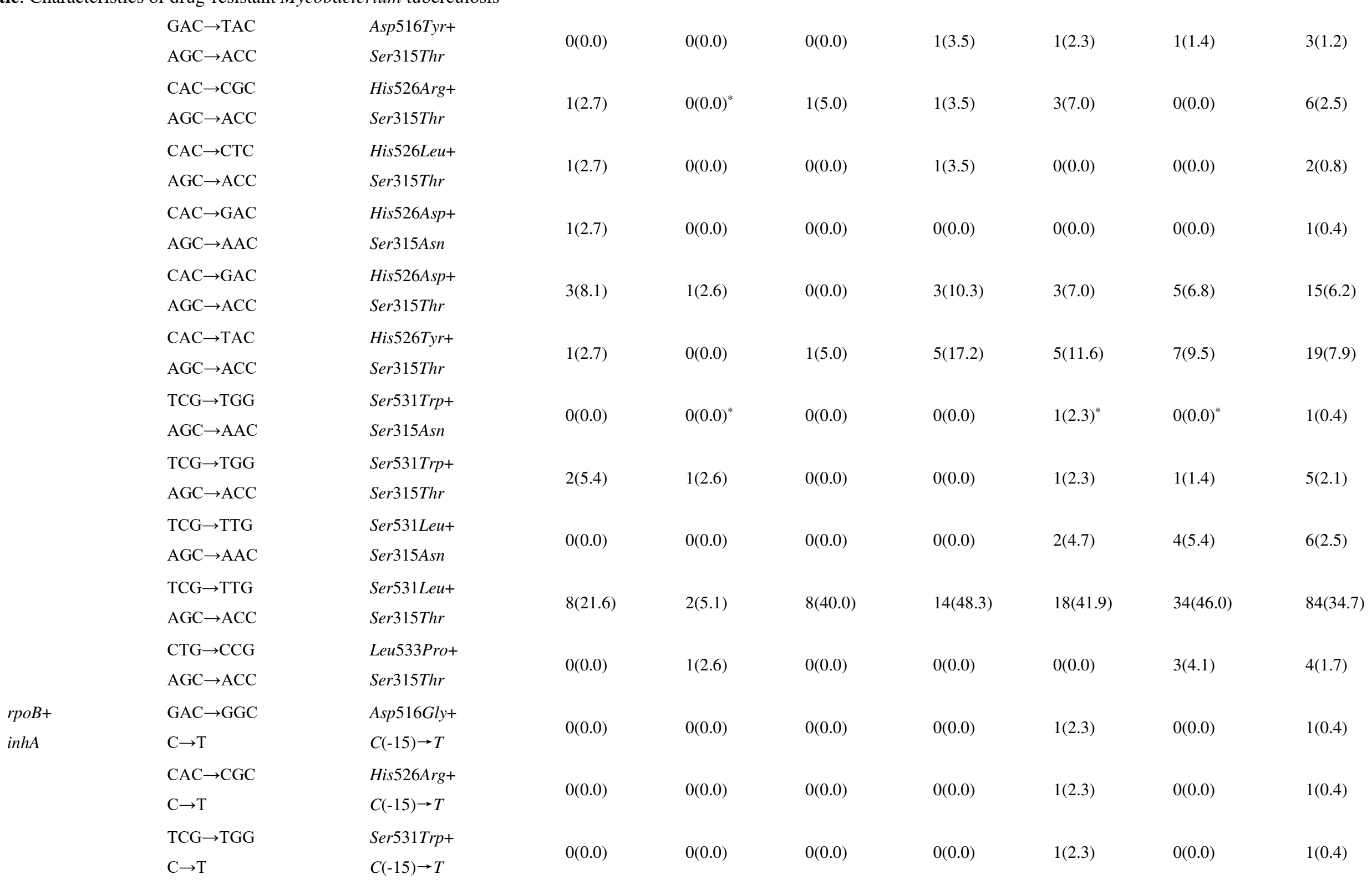


Running Title: Characteristics of drug-resistant Mycobacterium tuberculosis

\begin{tabular}{|c|c|c|c|c|c|c|c|c|c|}
\hline & $\begin{array}{l}\mathrm{TCG} \rightarrow \mathrm{TTG} \\
\mathrm{C} \rightarrow \mathrm{T}\end{array}$ & $\begin{array}{l}\text { Ser531Leu+ } \\
C(-15) \rightarrow T\end{array}$ & $0(0.0)$ & $0(0.0)$ & $1(5.0)$ & $2(6.9)$ & $1(2.3)$ & $1(1.4)$ & $5(2.1)$ \\
\hline rpoB+ & $\mathrm{CTG} \rightarrow \mathrm{CCG}^{+}$ & Leu511Pro+ & & & & & & & \\
\hline rpoB+ & $\mathrm{GAC} \rightarrow \mathrm{GGC}+$ & Asp516Gly & $1(2.7)$ & $0(0.0)$ & $0(0.0)$ & $1(3.5)$ & $0(0.0)$ & $0(0.0)$ & $2(0.8)$ \\
\hline \multirow[t]{16}{*}{ KatG } & $\mathrm{AGC} \rightarrow \mathrm{ACC}$ & Ser315Thr & & & & & & & \\
\hline & $\mathrm{CTG} \rightarrow \mathrm{CCG}^{+}$ & Leu511Pro+ & & & & & & & \\
\hline & $\mathrm{GAC} \rightarrow \mathrm{GTC}+$ & Asp516Val+ & $0(0.0)$ & $0(0.0)$ & $0(0.0)$ & $0(0.0)$ & $0(0.0)$ & $1(1.4)$ & $1(0.4)$ \\
\hline & $\mathrm{AGC} \rightarrow \mathrm{ACC}$ & Ser315Thr & & & & & & & \\
\hline & $\mathrm{CTG} \rightarrow \mathrm{CCG}^{+}$ & Leu511Pro+ & & & & & & & \\
\hline & $\mathrm{CAC} \rightarrow \mathrm{TAC}+$ & His526Tyrt & $0(0.0)$ & $0(0.0)$ & $0(0.0)$ & $0(0.0)$ & $0(0.0)$ & $1(1.4)$ & $1(0.4)$ \\
\hline & $\mathrm{AGC} \rightarrow \mathrm{ACC}$ & Ser315Thr & & & & & & & \\
\hline & $\mathrm{CAA} \rightarrow \mathrm{CCA}^{+}$ & Gln513Pro+ & & & & & & & \\
\hline & $\mathrm{GAC} \rightarrow \mathrm{GTC}+$ & Asp516Val+ & $0(0.0)$ & $0(0.0)$ & $0(0.0)$ & $0(0.0)$ & $0(0.0)$ & $1(1.4)$ & $1(0.4)$ \\
\hline & $\mathrm{AGC} \rightarrow \mathrm{ACC}$ & Ser315Thr & & & & & & & \\
\hline & $\mathrm{GAC} \rightarrow \mathrm{GGC}+$ & Asp516Gly+ & & & & & & & \\
\hline & $\mathrm{CTG} \rightarrow \mathrm{CCG}^{+}$ & Leu533Pro+ & $2(5.4)$ & $0(0.0)$ & $0(0.0)$ & $0(0.0)$ & $0(0.0)$ & $0(0.0)$ & $2(0.8)$ \\
\hline & $\mathrm{AGC} \rightarrow \mathrm{AAC}$ & Ser315Asn & & & & & & & \\
\hline & $\mathrm{GAC} \rightarrow \mathrm{GGC}+$ & Asp516Gly+ & & & & & & & \\
\hline & $\mathrm{CTG} \rightarrow \mathrm{CCG}^{+}$ & Leu533Pro+ & $0(0.0)$ & $0(0.0)$ & $0(0.0)$ & $0(0.0)$ & $0(0.0)$ & $1(1.4)$ & $1(0.4)$ \\
\hline & $\mathrm{AGC} \rightarrow \mathrm{ACC}$ & Ser315Thr & & & & & & & \\
\hline rpoB+ & $\mathrm{TCG} \rightarrow \mathrm{TTG}^{+}$ & Ser531Leu+ & & & & & & & \\
\hline KatG+ & $\mathrm{AGC} \rightarrow \mathrm{ACC}$ & Ser315Thr+ & $0(0.0)$ & $0(0.0)$ & $0(0.0)$ & $0(0.0)$ & $0(0.0)$ & $3(4.1)$ & $3(1.2)$ \\
\hline $\operatorname{inh} A$ & $\mathrm{C} \rightarrow \mathrm{T}$ & $C(-15) \rightarrow T$ & & & & & & & \\
\hline Other locus & Other mutations & Other substitutions & $6(16.2)$ & $34(87.2)^{*}$ & $9(45.0)^{*}$ & $0(0.0)^{*}$ & $0(0.0)^{*}$ & $2(2.8)^{*}$ & $51(21.1)$ \\
\hline Total & & & $37(100.0)$ & $39(100.0)$ & $20(100.0)$ & $29(100.0)$ & $43(100.0)$ & $74(100.0)$ & $242(100$ \\
\hline
\end{tabular}


Running Title: Characteristics of drug-resistant Mycobacterium tuberculosis

434

435

436

437

438

439

440

441

442

443

444

445

446

447

448

449

450

451

452

453

454

455

456

457

458

459

460

461

462

463

464

465

466

467

468

469

470

471

472

473

474

475

476

477

\section{References}

1. Krishna M, Gole SG: Comparison of Conventional Ziehl-Neelsen Method of Acid Fast Bacilli with Modified Bleach Method in Tuberculous Lymphadenitis. J Cytol 2017, 34(4):188-192.

2. Vilchèze $C$, Jacobs WR, Jr.: The Isoniazid Paradigm of Killing, Resistance, and Persistence in Mycobacterium tuberculosis. J Mol Biol 2019, 431(18):3450-3461.

3. Yang X, Yuan T, Ma R, Chacko KI, Smith M, Deikus G, Sebra R, Kasarskis A, van Bakel H, Franzblau SG et al: Mce3R Stress-Resistance Pathway Is Vulnerable to Small-Molecule Targeting That Improves Tuberculosis Drug Activities. ACS Infect Dis 2019, 5(7):1239-1251.

4. Chen S, Guo L, Wang Z, Mao W, Ge Y, Ying X, Fang J, Long Q, Liu Q, Xiang H et al: Current situation and progress toward the $\mathbf{2 0 3 0}$ health-related Sustainable Development Goals in China: A systematic analysis. PLoS Med 2019, 16(11).

5. He XC, Zhang XX, Zhao JN, Liu Y, Yu CB, Yang GR, Li HC: Epidemiological Trends of Drug-Resistant Tuberculosis in China From 2007 to 2014: A Retrospective Study. Medicine 2016, 95(15):0000000000003336.

6. Gebreweld FH, Kifle MM, Gebremicheal FE, Simel LL, Gezae MM, Ghebreyesus SS, Mengsteab YT, Wahd NG: Factors influencing adherence to tuberculosis treatment in Asmara, Eritrea: a qualitative study. J Health Popul Nutr 2018, 37(1):017-0132.

7. Nguyen L: Antibiotic resistance mechanisms in M. tuberculosis: an update. Arch Toxicol 2016, 90(7):1585-1604.

8. Zhao LL, Chen Y, Chen ZN, Liu HC, Hu PL, Sun Q, Zhao XQ, Jiang Y, Li GL, Tan YH et al: Prevalence and molecular characteristics of drug-resistant Mycobacterium tuberculosis in Hunan, China. (1098-6596 (Electronic)).

9. Yin QQ, Jiao WW, Li QJ, Xu F, Li JQ, Sun L, Li YJ, Huang HR, Shen AD: Prevalence and molecular characteristics of drug-resistant Mycobacterium tuberculosis in Beijing, China: 2006 versus 2012. BMC Microbiol 2016, 16(85):016-0699.

10. Guo Y, Zhou Y, Wang C, Zhu L, Wang S, Li Q, Jiang G, Zhao B, Huang H, Yu H et al: Rapid, accurate determination of multidrug resistance in $M$. tuberculosis isolates and sputum using a biochip system. Int J Tuberc Lung Dis 2009, 13(7):914-920.

11. Kigozi E, Kasule GW, Musisi K, Lukoye D, Kyobe S, Katabazi FA, Wampande EM, Joloba ML, Kateete DP: Prevalence and patterns of rifampicin and isoniazid resistance conferring mutations in Mycobacterium tuberculosis isolates from Uganda. PLoS One 2018, 13(5).

12. Tadesse M, Aragaw D, Dimah B, Efa F, Abdella K, Kebede W, Abdissa K, Abebe G: Drug resistance-conferring mutations in Mycobacterium tuberculosis from pulmonary tuberculosis patients in Southwest Ethiopia. Int J Mycobacteriol 2016, 5(2):185-191.

13. Chen L, Pang Y, Ma L, Yang H, Ru H, Yang X, Yan S, Jia M, Xu L: First Insight into the Molecular Epidemiology of Mycobacterium tuberculosis Isolates from the Minority Enclaves of Southwestern China. Biomed Res Int 2017, 2505172(10):17.

14. Luo D, Chen Q, Xiong G, Peng Y, Liu T, Chen X, Zeng L, Chen K: Prevalence and molecular characterization of multidrug-resistant M. tuberculosis in Jiangxi province, China. Sci Rep 2019, 9(1):019-43547.

15. Yu XL, Wen ZL, Chen GZ, Li R, Ding BB, Yao YF, Li Y, Wu H, Guo XK, Wang HH et al: Molecular characterization of multidrug-resistant Mycobacterium tuberculosis isolated from south-central in China. J Antibiot 2014, 67(4):291-297. 
Running Title: Characteristics of drug-resistant Mycobacterium tuberculosis

16. Zhang Z, Liu M, Wang Y, Pang Y, Kam KM, Zhao Y: Molecular and phenotypic characterization of multidrug-resistant Mycobacterium tuberculosis isolates resistant to kanamycin, amikacin, and capreomycin in China. Eur J Clin Microbiol Infect Dis 2014, 33(11):1959-1966.

17. Zhao LL, Chen Y, Chen ZN, Liu HC, Hu PL, Sun Q, Zhao XQ, Jiang Y, Li GL, Tan YH et al: Prevalence and molecular characteristics of drug-resistant Mycobacterium tuberculosis in Hunan, China. Antimicrob Agents Chemother 2014, 58(6):3475-3480.

18. Zhao LL, Chen Y, Liu HC, Xia Q, Wu XC, Sun Q, Zhao XQ, Li GL, Liu ZG, Wan KL: Molecular characterization of multidrug-resistant Mycobacterium tuberculosis isolates from China. Antimicrob Agents Chemother 2014, 58(4):1997-2005.

19. Rosser A, Marx FM, Pareek M: Recurrent tuberculosis in the pre-elimination era. Int J Tuberc Lung Dis 2018, 22(2):139-150.

20. Liao S, Cai C, Huo FM, Wu JN, Kong CC, Huang HR, Xu SF, Sun ZG: Trends in drug-resistant tuberculosis in China: data from a clinical tuberculosis centre. (1815-7920 (Electronic)).

21. Chen MY, Lo YC, Chen WC, Wang KF, Chan PC: Recurrence after Successful Treatment of Multidrug-Resistant Tuberculosis in Taiwan. PLoS One 2017, 12(1).

22. Timire C, Metcalfe JZ, Chirenda J, Scholten JN, Manyame-Murwira B, Ngwenya M, Matambo R, Charambira K, Mutunzi $\mathrm{H}$, Kalisvaart $\mathrm{N}$ et al: Prevalence of drug-resistant tuberculosis in Zimbabwe: A health facility-based cross-sectional survey. Int J Infect Dis 2019, 87:119-125.

23. Faustini A, Hall Aj Fau - Perucci CA, Perucci CA, Harausz EA-O, Garcia-Prats AJ, Law S, Schaaf HS, Kredo T, Seddon JA-O, Menzies D et al: Risk factors for multidrug resistant tuberculosis in Europe: a systematic review

Treatment and outcomes in children with multidrug-resistant tuberculosis: A systematic review and individual patient data meta-analysis

Risk factors for tuberculosis in foreign-born people (FBP) in Italy: a systematic review and meta-analysis

Systematic review, meta-analysis and economic modelling of molecular diagnostic tests for antibiotic resistance in tuberculosis

Is HIV infection a risk factor for multi-drug resistant tuberculosis? A systematic review. (0040-6376 (Print)).

24. Yin QQ, Jiao WW, Li QJ, Xu F, Li JQ, Sun L, Li YJ, Huang HR, Shen AD: Prevalence and molecular characteristics of drug-resistant Mycobacterium tuberculosis in Beijing, China: 2006 versus 2012. (1471-2180 (Electronic)).

25. Lu Z, Jiang W, Zhang J, Lynn HS, Chen Y, Zhang S, Ma Z, Geng P, Guo X, Zhang H et al: Drug resistance and epidemiology characteristics of multidrug-resistant tuberculosis patients in 17 provinces of China. PLoS One 2019, 14(11):e0225361.

26. Li Q, Wang Y, Li Y, Gao H, Zhang Z, Feng F, Dai E: Characterisation of drug resistance-associated mutations among clinical multidrug-resistant Mycobacterium tuberculosis isolates from Hebei Province, China. Journal of Global Antimicrobial Resistance 2019, 18:168-176.

27. Liu L, Jiang F, Chen L, Zhao B, Dong J, Sun L, Zhu Y, Liu B, Zhou Y, Yang J et al: The impact of combined gene mutations in inhA and ahpC genes on high levels of isoniazid resistance amongst katG non-315 in multidrug-resistant tuberculosis isolates from China. Emerg Microbes Infect 2018, 7(1):018-0184.

28. Llerena C, Medina R: [Description of Mycobacterium tuberculosis mutations conferring 
Running Title: Characteristics of drug-resistant Mycobacterium tuberculosis

resistance to rifampicin and isoniazid detected by GenoType ${ }^{\circledR}$ MTBDRplus V.2 in Colombia]. Biomedica 2017, 37(1):28-33.

29. Matsui T, Pinhata JMW, Rabello M, Brandão AP, Ferrazoli L, Leão SC, Viana-Niero C, Oliveira RS: Frequency of first and second-line drug resistance-associated mutations among resistant Mycobacterium tuberculosis clinical isolates from São Paulo, Brazil. (1678-8060 (Electronic)).

30. Jagielski T, Bakuła Z, Roeske K, Kamiński M, Napiórkowska A, Augustynowicz-Kopeć E, Zwolska $\mathrm{Z}$, Bielecki J: Mutation profiling for detection of isoniazid resistance in Mycobacterium tuberculosis clinical isolates. J Antimicrob Chemother 2015, 70(12):3214-3221.

31. Li Q, Wang Y, Li Y, Gao H, Zhang Z, Feng F, Dai E: Characterisation of drug resistance-associated mutations among clinical multidrug-resistant Mycobacterium tuberculosis isolates from Hebei Province, China. J Glob Antimicrob Resist 2019, 18:168-176.

32. Isakova J, Sovkhozova N, Vinnikov D, Goncharova Z, Talaibekova E, Aldasheva N, Aldashev A: Mutations of rpoB, katG, inhA and ahp genes in rifampicin and isoniazid-resistant Mycobacterium tuberculosis in Kyrgyz Republic. BMC Microbiol 2018, 18(1):018-1168.

33. Kanji A, Hasan R, Hasan Z: Efflux pump as alternate mechanism for drug resistance in Mycobacterium tuberculosis. (0019-5707 (Print)). 
Figures

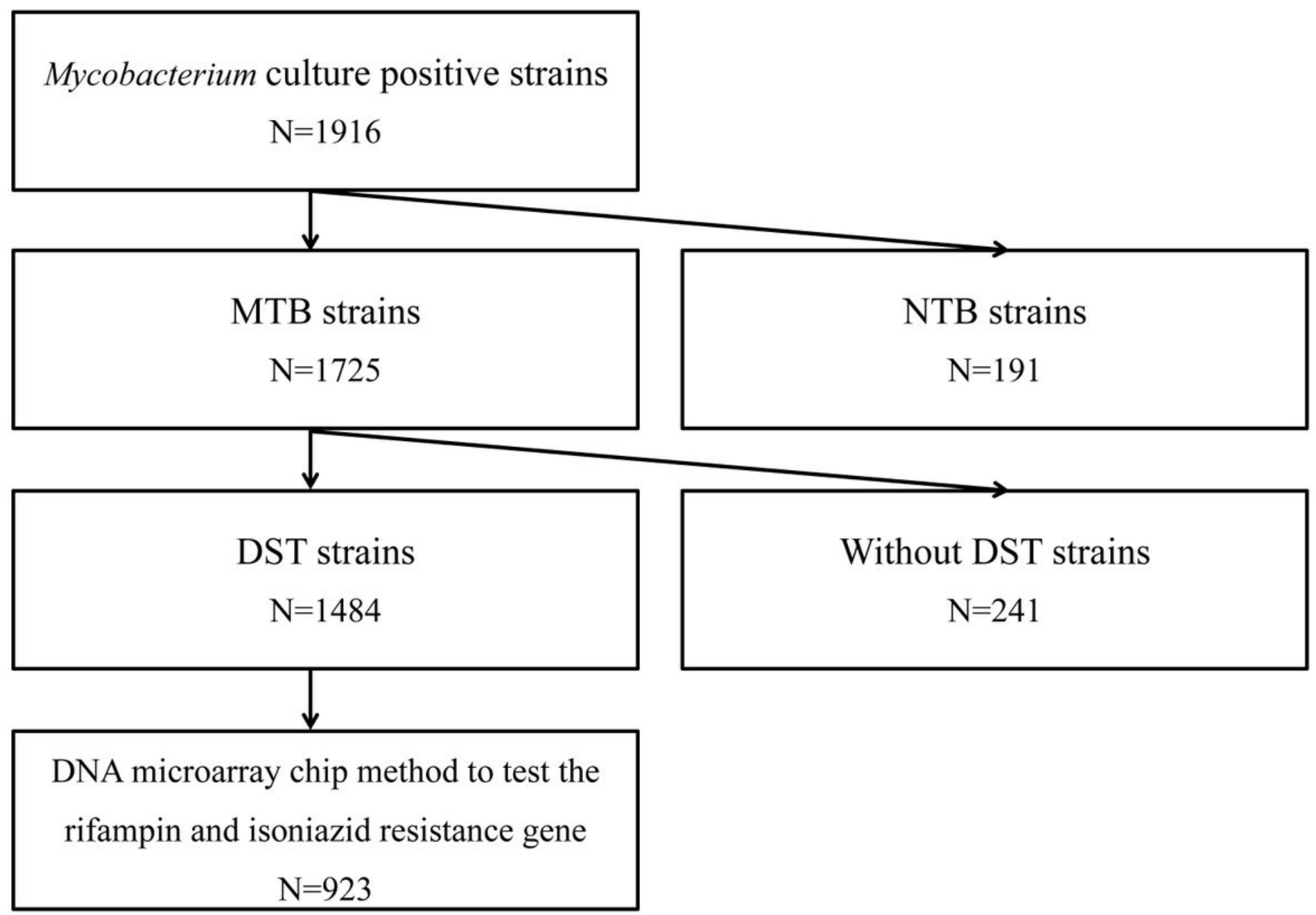

Figure 1

Inclusion and Exclusion of the study objects. MTB: mycobacterium tuberculosis; NTB: non-tuberculosis; DST: drug susceptibility test. 


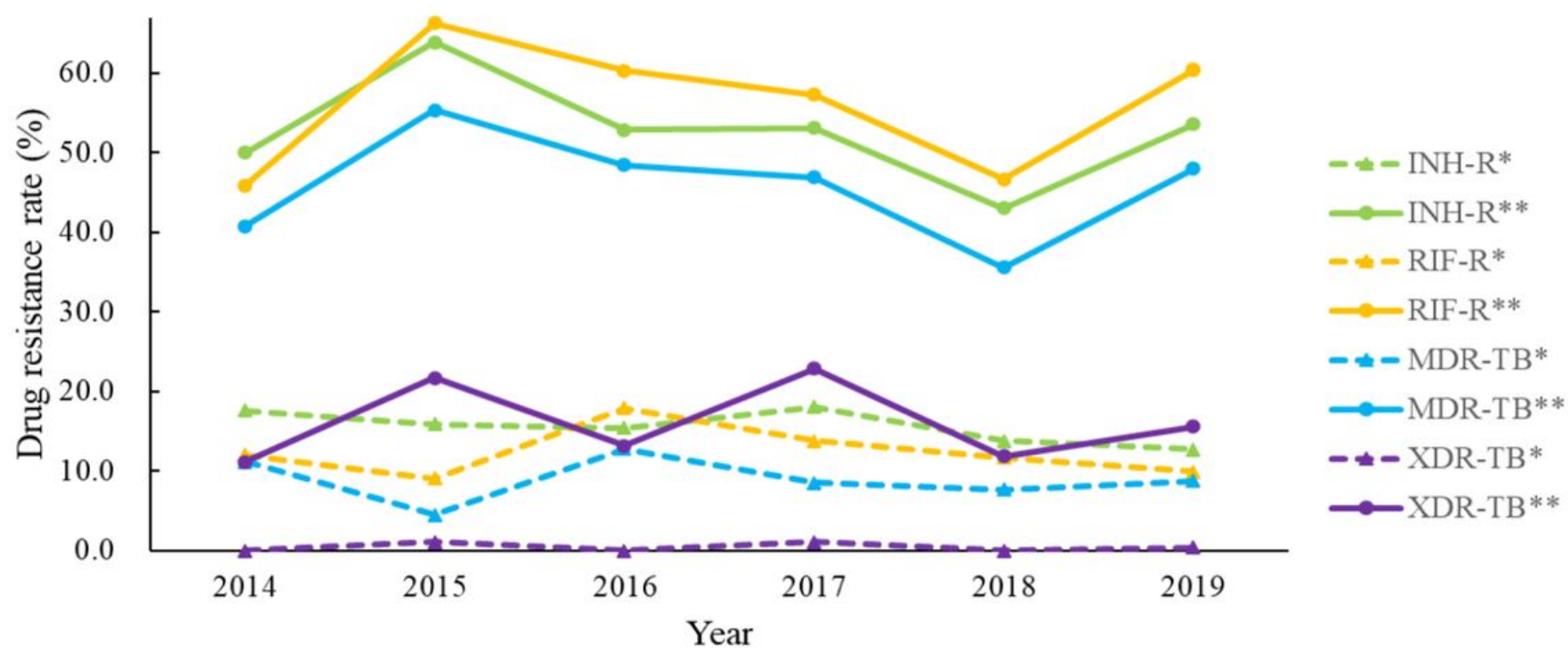

\section{Figure 2}

Trends of different drug-resistance patterns among 1484 culture-confirmed TB cases in Hainan, 2014 to 2019. In new cases, for INH resistance $(\chi 2=2.813,416 P=0.729)$; for $R I F$ resistance $(\chi 2=3.181, P=0.672)$; for MDR-TB $(\chi 2=4.210, P=0.520)$; for XDR-TB $(\chi 2=4.383, P=0.496)$. In retreatment cases, for INH resistance $(X 2=9.512,417 P=0.090)$; for $R I F$ resistance $(X 2=14.257, P=0.014)$; for MDR-TB $(X 2=10.328$, $\mathrm{P}=0.066)$; for $\mathrm{XDR}-\mathrm{TB}(\mathrm{X} 2=7.670, \mathrm{P}=0.175)$. Note: *new cases, ** retreatment cases. Abbreviation: INH-R, isoniazid resistance; RIF-R, rifampin resistance; MDR-TB, multidrug resistant mycobacterium tuberculosis; XDR-TB, extensively drug resistant mycobacterium tuberculosis.

\section{Supplementary Files}

This is a list of supplementary files associated with this preprint. Click to download.

- Oligonucleotideprobesandprimersusedinthisstudy.pdf 